\title{
Interpelación a las ciencias sociales:el desafío de comprender la sociedad contemporánea
}

\author{
Marcelo ARNOLD-CATHALIFAUD \\ Facultad de Ciencias Sociales, Universidad de Chile
}

\begin{abstract}
RESUMEN
La región latinoamericana necesita de unas ciencias sociales institucionalmente robustas, críticas y a la vez rigurosas; disciplinas que contribuyan al esclarecimiento de la sociedad contemporánea y que respondan a sus demandas sociales más urgentes. El presente artículo discute alternativas para que nuestras investigaciones, a nivel local, regional y global, aborden productivamente los cambiantes escenarios que caracterizan las primeras décadas de este siglo. La exposición, en primer lugar, analiza cómo nuestras disciplinas enfrentan la demanda de conocimientos en el actual contexto global; en segundo lugar, destaca obstáculos, internos y externos, que inhiben el despliegue de sus aportes, y finalmente presenta una oferta programática, inspirada en las teorías de sistemas y de la complejidad con énfasis en su pertinencia para América Latina.
\end{abstract}

Palabras Clave: Latinoamérica, sociedad, ciencias sociales, teoría de sistemas, complejidad.

\section{Interpellation to the Social Sciences: the challenge of understanding contemporary society}

\begin{abstract}
Latin America needs robust, critical and rigorous social sciences from an institutional approach; it needs disciplines that contribute to the understanding of contemporary society and to meet its urgent social demands. This article presents alternatives to address productively the changing scenarios that characterized the first decades of this century at local, regional and global levels in our researches. First, the exposition analyzes how our disciplines face the demand for knowledge in the current global context; secondly, it emphasizes internal and external obstacles that inhibit their contributions deployment, and finally it presents a programmatic proposal, inspired by the systems and complexity theories emphasizing its relevance for Latin America.
\end{abstract}

Keywords: Latin America, Society, Social Science, Systems Theory, Complexity. 
omo punto de partida puede señalarse que los modos de operar y los
efectos de la actividad científica se han generalizado en la sociedad
- hoy mundial-. Este expectable posicionamiento guarda relación tanto con los condicionamientos que generan sus prestaciones como por la inflación de expectativas que se suscitan ante lo que se espera de ellas. Aunque las ciencias sociales no lideran estos reconocimientos, se desarrollan, y por tanto pueden aprovechar, ese favorable contexto, en particular cuando nociones como sociedad del conocimiento o sociedad de la información (UNESCO 2005; Castells 1966) destacan la importancia de contar con una comprensión más completa de la sociedad, tanto en el plano de su caracterización estructural como de sus dinámicas.

La importancia de los conocimientos que pueden producir las ciencias sociales y la información que desde ellos se comunica a la sociedad no es desestimable. Los acelerados cambios y recurrentes crisis que acontecen en el planeta han contribuido en incrementar un mayor interés por estudiar los procesos sociales, especialmente el anhelo de anticipar sus tendencias se constituye en una importante motivación. Consecuentemente, se han intensificado las peticiones de parte de organismos internacionales, gobiernos, corporaciones y asociaciones de la sociedad civil por contar con conocimientos especializados sobre las actuales condiciones sociales. Estos requerimientos se proyectan en prestaciones que concurren para seleccionar o legitimar decisiones sobre políticas públicas, como también en informaciones que apoyan estrategias comerciales que afectan a personas, comunidades, países o al mundo entero. Paralelamente, con gran impacto en el plano de la convivencia cotidiana, los medios de comunicación para las masas construyen muchas de sus noticias desde conocimientos de las ciencias sociales que vinculan con temas de expectación pública. Así, mientras la sociedad se realiza y evoluciona, se acogen y diseminan informaciones originadas en centros académicos, organismos internacionales, agencias estatales, organizaciones no gubernamentales, estudios privados (think tanks) o empresas periodísticas que encargan estudios sociales. Todas estas comunicaciones adquieren especial relevancia cada vez que la participación y deliberación ciudadana parece desbordarse y, en muchos casos, los conocimientos certificados por una nueva expertocracia "sociológica" son utilizados para provocar, apoyar, contener o clausurar discusiones ciudadanas.

Sin embargo, las ciencias sociales no se limitan a proporcionar informaciones con efectos funcionales que mantienen o controlan el statu quo.

\section{8/ REVISTA DE SOCIOLOGÍA 25}


También producen conocimientos críticos o emancipadores que abastecen de estrategias, datos y argumentos a organizaciones de la sociedad civil y a movimientos sociales que promueven causas o luchan por reivindicaciones; además atienden al requerimiento de procedimientos y criterios para evaluar estadísticas, informaciones oficiales o encuestas que influyen en la opinión pública y en los grupos decisores. Junto a lo anterior, estas disciplinas proporcionan herramientas y tecnologías que son indispensables para canalizar demandas, defender o promover derechos, advertir o dar cuenta sobre injusticias $y$ actos discriminatorios. Es por eso que inclusive quienes proponen cambios estructurales profundos y desconfían de las instituciones - la ciencia incluida-, encuentran inspiración en comunicaciones sociológicas. En la práctica, no se espera todo del "inevitable curso de la historia", de la marcha callejera o de eslóganes inspiradores. La necesidad de conocimiento fundamentado se agudiza cuando deben confrontarse propuestas y exponerlas a debate.

No obstante lo anterior, mientras aumenta la demanda de conocimientos sobre los procesos sociales, la aceleración de los cambios y la creciente diferenciación interna de la sociedad, dificultan, más que antes, identificar o anticipar las relaciones entre sus componentes y dar cuenta de sus tendencias. De estas dificultades surgen muchas frustraciones, pero no hay que desanimarse ante ellas, las disciplinas científicas están provistas de recursos para afrontarlas. Justamente, las operaciones de la ciencia se sustentan y organizan desde el déficit de certezas pues, a diferencia de lo que ocurre con la inmutabilidad de los dogmas o el conservadurismo de las ideologías políticas, asumen como "normalidad" la provisionalidad de sus conocimientos y trabajan las incertidumbres manejando hipótesis. Por lo demás, ya no se ignora que los procesos sociales son extremadamente contingentes y dinámicos y que nunca se agota su conocimiento.

En síntesis, las ciencias sociales contemporáneas han visto ampliadas sus funciones investigativas, acreditadoras y también las emancipadoras. Estudiar sus estados, discutir sobre los contextos de producción y difusión de sus conocimientos, así como sus obstáculos, oportunidades, requerimientos y desafíos que enmarcan o dificultan su desenvolvimiento, se constituyen en temas relevantes. Nuestra región no escapa a esta norma.

Se da por hecho que, especialmente, las condiciones contextuales políticas y económicas se correlacionan con el nivel y tipo de desarrollo de las ciencias 
sociales. Así, por ejemplo, desde principios de la década de los ochenta, la expansión regional de las universidades privadas, al alero de las reformas neoliberales, alteró la tradicional institucionalidad de las ciencias sociales, al punto que actualmente la mayor proporción de estudiantes proviene de ese sector universitario. En las décadas siguientes se aprecia, con nitidez, un creciente volumen de graduados, profesionales e investigadores. De hecho, en poco tiempo la cantidad de investigadores se duplicó, la de estudiantes se triplicó y la de posgraduados aumentó casi diez veces (UNESCO-ISSC 2010:61). Sin embargo, a pesar de estas favorables condiciones, las producciones de las ciencias sociales regionales, salvo excepciones, no empalman con el reconocimiento científico e impacto social que se esperaría de ellas.

Las evidencias indican que, como siempre, nuestros acervos disciplinarios se producen en países occidentales desarrollados (Gingras \& MosbahNatanson 2010). Así, la comprensión de los fenómenos sociales se provee por una, cada vez más diversificada y accesible, producción de investigadores que se ocupan de ellos en centros estadounidenses, ingleses, franceses o alemanes. Esta realidad se ha reforzado con las posibilidades de la Internet, la internacionalización de las universidades y con las facilidades para los desplazamientos a nivel mundial. Sin embargo, no es evidente por qué estas ventajas son aprovechadas por los mismos de siempre. La disponibilidad de redes mundiales de comunicación que son indiferentes a la localización de las comunidades disciplinarias, deberían multiplicar los aportes desde regiones distantes de los centros tradicionales y podría esperarse que las nuevas condiciones faciliten la presencia de las ciencias sociales regionales en el contexto mundial. Como eso no ha ocurrido, se constituye como un problema que debe ser analizado con algún mayor detalle.

Un primer aspecto a considerar es que cuando se destacan malos indicadores en la producción de las ciencias sociales regionales, tal evaluación se hace bajo el sesgo de los parámetros de los centros de ciencias sociales hegemónicas (vid. Ranking Scimago). Esta observación es bastante razonable. Por ejemplo, el índice del Institute for Scientific Information - que nos ha contagiado con la ISImanía - se relaciona, indiscutiblemente, con la preferencia por publicaciones en inglés, lo que puede explicar el hecho que los mayores autores de artículos en ciencias sociales sean, hasta ahora, anglosajones (Ammon 2010). La barrera lingüística, ciertamente, favorece reproducir y acrecentar una asimetría entre la producción y la generalización de los conocimientos de las ciencias sociales y se entrelaza con dependencias afianzadas en las dimensiones económica y política de la sociedad. Pero, cualquiera que sea la

\section{0/ REVISTA DE SOCIOLOGÍA 25}


causa o la función que se les atribuya, el hecho que se establezcan condiciones desmejoradas de competitividad para las producciones regionales, somete a los investigadores a la presión por publicar artículos en formatos foráneos, lo cual los lleva a desinteresarse de sus audiencias locales y, por extensión, a desentenderse de los temas de interés regionales. Hay excepciones, pero las probabilidades van en la dirección antes sugerida.

Si bien la normalización forzada de la comunicación científica puede y es resistida por muchos miembros de las comunidades disciplinarias regionales, los efectos de su oposición se proyectan en exclusiones. En los hechos, olvidarse de las revistas ISI y publicar en medios locales afecta las carreras académicas y limita directamente al acceso a fondos para proyectos. Así, los investigadores se ven enfrentados a decisiones trágicas del tipo "publique papers en revistas indexadas en idioma inglés y sométase a sus estándares" o "hágalo como quiera, pero asuma las consecuencias". Por otra parte, las instituciones regionales de ciencias sociales que no atienden el llamado a integrarse a estas normas, conviven con dificultades para mejorar su presupuesto e incluso para conservar o justificar el que tienen. En ese camino, se potencia un ciclo regresivo: las publicaciones locales decaen, finalmente los estudiosos y los investigadores, como la opinión pública, deben informarse sobre lo que ocurre en sus propias calles en inglés y en revistas extranjeras. Así, uno de los desafíos más importantes de las ciencias sociales regionales, esto es, comprender nuestras realidades, y difundir su comprensión, queda pendiente.

No obstante los reparos destacados, observadas desde otros planos las consecuencias de la normalización de la comunicación científica no son solamente negativas. En este aspecto, podría considerarse oportunidad que las ciencias sociales enfrenten su “Torre de Babel”. Por ejemplo, la generalización de formatos facilita la difusión de la comunicación científica, permite que sus producciones se encadenen unas con otras y que nuevas evidencias, con sus respectivas argumentaciones, se expongan y confronten ante públicos más extensos y diversos. Por otro lado, aunque per se los criterios estandarizados no garantizan calidad, apartarse de ellos disminuye las posibilidades de difundir investigaciones locales, lo cual redunda en que la comprensión de la sociedad global y de sus procesos quede sin alternativas, librada a descripciones parciales. Finalmente, debe hacerse notar, para no sucumbir ante la imagen de una irremediable dependencia, que los centros de influencia en ciencias sociales, como la sociedad entera, también se modifican (como está ocurriendo). De hecho, las normas que actualmente regulan la actividad 
científica ofrecen la posibilidad de actuar sobre los criterios que, en algún momento, operan como sus directrices centrales. No es imposible que cambien las hegemonías lingüísticas o que, al menos, se intensifique la exigencia de presentar resúmenes de publicaciones y presentaciones orales en distintos idiomas. De hecho la industria de traducciones en línea está en una acelerada perfección de sus servicios y tecnologías.

Por otra parte, si bien las producciones europeas y estadounidenses acaparan actualmente casi las tres cuartas partes de las publicaciones disciplinarias, merece atención el hecho que no todos los conocimientos relevantes en ciencias sociales se han originado en sus centros. En este sentido, examinar aportes regionales, de reconocido nivel internacional, entrega muchas lecciones. Por nombrar ejemplos, la teoría de la modernización asincrónica desarrollada por Germani (1962), la teoría de la dependencia, en la versión de Cardoso y Faletto (1969), la teoría evolucionista de Ribeiro (1976) o la teología de la liberación, que destaca una interpretación de la cultura. Estos casos, a los cuales podrían agregarse otros (e.o. Domínguez, 2013), permiten identificar algunos factores que, más allá de las dificultades que pone la formalidad de las comunicaciones científicas, favorecen la conectividad científica y la estabilización de conocimientos regionales ante públicos más extensos y especializados. En los casos mencionados se destaca la vinculación de las producciones aludidas con procesos sociales y teorías de alcance global. Sin embargo, la limitada emulación de estas formas de investigar conduce a relevar como otra explicación para la desmedrada posición de nuestras producciones disciplinarias en el escenario global, un aparente descuido de nuestras propias producciones, lo que podría considerarse como un tipo de auto-colonialismo disciplinario.

Aunque no hemos explorado el fondo que sostendría la (auto)desvalorización de nuestras producciones regionales sospechamos que, en general, se las considera poco rigurosas o de baja calidad. Si bien esta impresión pudiera corresponder a parte de ellas, no explica que incluso investigadores latinoamericanos consagrados a nivel mundial no sean adecuadamente reconocidos y que se siga esperando en autores foráneos la inspiración, o reconocimiento, para comprender nuestras realidades. El caso de los aportes epistemológicos de Humberto Maturana y Francisco Varela (1973) y su concepto de autopoiesis es paradigmático (ver Arnold et al 2011). En este caso pareciera, a diferencia de lo ocurrido en nuestra región, que los investigadores europeos y anglosajones no hicieron cuestión de la chilenidad del abstracto concepto de autopoiesis para darle reconocimiento y aplicarlo en sus teorías sobre la sociedad (e.o.

\section{2/ REVIISTA DE SOCIOLOGÍA 25}


Luhmann 1986). Estas últimas observaciones apuntan al rol que jugarían las expectativas de nuestras comunidades respecto del valor de las producciones de investigadores locales y también sobre los obstáculos que colocan para evitar ponerlas, a nivel global, en las primeras líneas de sus disciplinas.

Con respecto a lo anterior, cabe indicar que en los últimos decenios importantes intelectuales latinoamericanos vinculados con las humanidades, la literatura y los estudios culturales, intentando influir en la matriz hegemónica de las ciencias sociales, han promovido la valorización de nuestras producciones regionales ${ }^{1}$. De partida proponen, y eso es muy positivo, atender nuestra diversidad y particularismos regionales y dejar de "leerlos" como condiciones sociales incompletas, marginales o atrasadas (e.o. Quijano 2000). Esta opción los ha constituido en un modelo y referente para superar nuestra dependencia de los actuales centros productores de ciencias sociales. Lamentablemente, corresponde indicar, algunas de las propuestas de esta corriente, interpretadas exageradamente, podrían tener efectos desestimables. Dada su influencia y su valiosa postura reivindicativa del conocimiento local me extenderé en algunos comentarios sobre ello.

El ejercicio de deconstruir las perspectivas hegemónicas con que las ciencias sociales explican la sociedad y sus procesos es revelador, pero poner en duda, por principio, la pretensión de universalidad de los conocimientos científicos sobre los fenómenos sociales no es así de aceptable. Al menos su rendimiento, como se apreció para el caso de las corrientes posmodernistas, es muy incierto (aunque ello no ha limitado su impacto). Ciertamente en Latinoamérica conviven países muy heterogéneos, no modernizados, jerárquicos, extremadamente desiguales y excluyentes, aparentemente muy distintos a las realidades desde donde han surgido las teorías sociológicas clásicas y contemporáneas. No obstante, sobre esa constatación no puede avalarse la descalificación de las ciencias sociales. Más aún, valorar los conocimientos según su procedencia (falacia genética), como reza un conocido proverbio, conduce a botar el agua de la bañera junto con el niño.

La pretensión universalista de las ciencias sociales, bien entendida y aplicada, ha sido un aliciente para abordar tanto la pluralidad como la especificidad de las expresiones sociales, no equivale por tanto a someterse a una racionalidad anglo-eurocéntrica, tampoco lleva a confundir una visión hegemónica con lo universal o a tener que interpretar las diferencias regionales o locales como defectos. Ciertamente, para el caso, la modernidad latinoame-

1 Una completa síntesis de las principales tendencias de las ciencias sociales regionales en Germaná 2009. 
ricana no puede presuponerse como una versión imperfecta de la europea o la estadounidense, sino como una de las manifestaciones de un proceso social que ocurre en ciertas condiciones económicas, políticas y culturales. Por eso, las perspectivas críticas regionales tienen toda la razón cuando enfrentan concepciones anglo-eurocéntricas fundamentadas etnocéntricamente, pero yerran al darles el carácter de científicas, y doblemente al descalificar, por lo mismo, a aquellas que sí son rigurosas. Para mayor abundamiento, teorías como el materialismo histórico, el psicoanálisis, el estructuralismo o las de sistemas, debido a su nivel de abstracción, han sido capaces de abordar una diversidad de manifestaciones sociales y humanas específicas sin dejar de considerar sus patrones comunes y sin llegar a afirmarse como dogmas.

Mientras no se aporten mejores argumentos o métodos alternativos, las "desobediencias epistémicas" o las "sospechas radicales" (e.o. Mignolo 2010) en los términos que se proclaman, pueden tener como efecto relajar la rigurosidad metodológica y los alcances de las investigaciones en ciencias sociales, haciendo perder de vista los criterios de aceptabilidad de sus conocimientos, los que no parece tan mal que se mantengan (y que no tienen nada que ver con la respetabilidad de explicaciones de otro tipo). En este sentido, concordamos con Fernando Robles (2012), quien, muy acertadamente, indica que este nuevo pensamiento latinoamericano debe ser reforzado en lo sociológico para así evitar algunas de sus incongruencias. En la misma línea, la indicación de Paulo Henrique Martins (2011), pasado Presidente de ALAS, es convincente cuando invita a construir una región del conocimiento inserta en el mundo global, que se caracterice por la producción de campos críticos no hegemónicos, pero promoviendo una integración creativa con la sociología clásica y moderna. En suma, se trata de evitar caer en los sesgos y malinterpretaciones de un universalismo anglo-eurocentrado, pero sin sucumbir en un particularismo relativista descontextualizado.

En suma, no debemos quedarnos lamentando una situación de dependencia - de la cual también somos responsables -, y tampoco adherir acríticamente a posturas que relativizan el quehacer científico y que solo llevan a desconsiderar sus logros. Se puede ser más propositivo.

Las producciones regionales podrían trabajarse mejor combinando lo particular (local) con lo general (global) y no esencializando lo primero, menos haciendo uso del etnocentrismo para combatir el etnocentrismo ajeno. Para ello, por ejemplo, cabe fomentar investigaciones de amplio alcance que aborden la globalización y sus actuales formas hegemónicas de subordinación de países e identidades locales; la revitalización de las diversidades sociales

\section{4/ REVISTA DE SOCIOLOGÍA 25}


y culturales; el resguardo de la memoria y patrimonio nacional; los efectos de las actuales crisis financieras en la seguridad social; las nuevas y crecientes desigualdades y exclusiones sociales; la devastación de los recursos medioambientales y el calentamiento global; la extendida violencia, inseguridad y maltrato en las grandes ciudades; las múltiples formas de corrupción; los acelerados cambios en la composición etaria de la población; el repliegue de los estados, la desprotección y el individualismo; las modificaciones de las pautas afectivas, sexuales y de género; los nuevos movimientos sociales y la emergencia de las redes sociales globales; la transformación de la impaciencia ciudadana en indignación o los desafíos de gobernabilidad internacional, entre muchos otros problemas. Todos estos temas-problemas se despliegan en el mundo contemporáneo, no son patrimonio de un país o región aunque, por supuesto, sus énfasis varían y por eso deben estudiarse. Por ejemplo, desde Latinoamérica se puede producir mucha reflexión disciplinaria sobre los conflictos y desigualdades que se relacionan con contextos de rápido e inequitativo crecimiento económico - si se quiere decir del modo acostumbrado: los efectos del neoliberalismo en países periféricos-.

Ciertamente, el fortalecimiento y posicionamiento global de las ciencias sociales regionales, acorde con sus actuales posibilidades y en los términos que hemos discutido, hasta aquí, no ocurrirá como un proceso natural y del cual solo el tiempo se hará cargo. Por mientras los efectos de una actitud de espera son equivalentes a lo que ocurre en una escalera mecánica: todos avanzan, pero las distancias permanecen (cuando no, ya algunos están en los otros pisos). Por eso, nada conviene menos que quedarse en la crítica de café o someternos pasivamente a las producciones científicas sin intervenir en su elaboración. En este sentido, cabría distinguir entre las ofertas programáticas disponibles en las ciencias sociales las que pueden contribuir a revertir las actuales tendencias. Es entre estas que se selecciona la de los sistemas y de la complejidad.

\section{III}

Como se ha señalado, en principio la sociología y las ciencias sociales podrían estar en un buen momento. Pero, si bien los conocimientos sobre la sociedad tienen una alta demanda y nuestras comunidades disciplinarias se han expandido en forma significativa, estas condiciones no han culminado en un círculo virtuoso. Las distancias entre las producciones disciplinarias con las 
expectativas revelan que las dinámicas sociales se adelantaron con mucho a su comprensión. En ese camino, las ciencias sociales regionales titubean y sus cultores se apuntan en el desconcierto. Cuando no parece suceder lo que pasaba y lo que acontece no se investiga adecuadamente, crisis e incertidumbre pasan a ser las palabras de moda. Si bien se han levantado algunas propuestas, los extravíos y exageraciones son frecuentes. En el intertanto, la necesidad de intervenir la sociedad se pone insistentemente sobre la mesa, pero los conocimientos fundamentados para el éxito de tal propósito escasean. En el camino, razonablemente, se declara que la principal demanda ética de la sociología es hacer buena sociología (Chernilo y Mascareño 2005: 44). Este diagnóstico podría considerarse con validez global, pero sus indicaciones son más evidentes para nuestra región.

Podríamos no tener la certeza de si la sociedad contemporánea efectivamente funciona en forma descoordinada o descontrolada, pero, en cualquier caso, puede afirmarse que no está lo suficientemente conocida. Ante el desafío de abordar los "grandes problemas contemporáneos", donde nada puede considerarse fijo, inmutable o definitivo, las teorías, conceptos y metodologías acostumbradas se aprecian limitadas. Más bien abundan barreras cognitivas que simplifican o ignoran los fenómenos sociales emergentes. Por eso, si se quiere ir más allá de reiterar una crítica puramente discursiva del estado de nuestras disciplinas, es necesario desbloquear obstáculos que impiden a nuestras disciplinas afrontar con mayor éxito sus desafíos cognoscitivos y prácticos. Para avanzar en ello un punto de partida es identificar "puntos ciegos" que impiden atender el carácter contingente de las expresiones sociales, tratar sus altos grados de incertidumbre, creciente variedad y condición heterárquica y acéntrica.

Examinar lo que ocurre en disciplinas que enfrentan problemas similares, puede ser aleccionador. Desde allí, entre otras ofertas con propósitos equivalentes, se destaca la opción de vincular las ciencias sociales con las teorías sistémicas y de la complejidad, pues estas resuenan más con las dinámicas e inesperadas transformaciones sociales contemporáneas. Por otro lado, las contribuciones que les han dado forma no se limitan a países ni líneas temáticas específicas. Estas corrientes ya han sido mencionadas, por ejemplo, el sociólogo peruano Julio Mejía afirma que como nunca en su historia América Latina participa en el cambio epistemológico fundado en las teorías de la complejidad (2009), esta idea es reforzada por su compatriota Molinari (2009). Algunos autores, especialmente quienes destacan su diversidad y versatilidad regional, han destacado su carácter policéntrico, estos en su mayor parte

\section{6/ REVISTA DE SOCIOLOGÍA 25}


sintonizan con las corrientes críticas y a la vez renovadoras (e.o. GonzálezCasanova 2009), o provienen de centros que se han permeado con el pensamiento de Edgar Morin o son muy sensibles a estas aproximaciones. Otros como el antropólogo Escobar (2003) plantean no enfatizar el particularismo frente a un falso o incompleto y deformado universalismo anglo-eurocentrado, sino que enfocarse en la multiplicidad; connotados filósofos como CastroGómez y Grosfoguel (2007) proponen conceptualizar las estructuras sociales con lenguajes que consideren la diversidad, reconozcan lógicas autónomas y que permitan abordar procesos heterogéneos y temporalidades múltiples. En conjunto, muchos intelectuales e investigadores de la región, cual más cual menos, consideran a las aproximaciones teóricas que combinan lo abstracto y universalista con el reconocimiento de las particularidades regionales 0 históricas latinoamericanas.

Colocar como centro de atención de las ciencias sociales las teorías de sistemas y de la complejidad tiene importantes fundamentos. Especialmente cuando mientras más conocemos, menos podemos considerar aisladamente o relacionar causalmente nuestros objetos de interés. Ni siquiera la modernidad europea podría desentenderse de que surge desde su traumático encuentro con un "nuevo mundo" (y con el desencuentro con otros tantos "mundos"), como señala convincentemente Dussel (2000).

En el actual contexto de globalización, los entrelazamientos son más evidentes. No puede reducirse la sociedad a una de sus manifestaciones, países o territorios específicos; tampoco es razonable ofrecer una comprensión sociológica de América Latina prescindiendo de sus vinculaciones con otras regiones. Por otra parte, carece de soportes pretender que las explicaciones acerca de los problemas, cambios o evolución la sociedad tengan que hacerse desde algunos países o regiones; tampoco la condición latinoamericana o la de la modernidad europea están auto-contenidas en sus límites o en sus actuales habitantes. De hecho, el pensamiento latinoamericano no es patrimonio de ningún país en particular, hasta puede desarrollarse en otra latitudes. Aplicarse en producir conocimientos sobre la sociedad de manera aislada solo lleva a descuidar el hecho de que procesos representados como muy particulares a nivel local o micro, responden a entrelazamientos a nivel global o macro.

Posicionar la dimensión social de la complejidad al centro de los debates tendría varias ventajas. Entre ellas una observación no reduccionista de los fenómenos sociales y una postura epistemológica constructivista, es decir desontologizada. Estas cualidades constituyen a una convincente oferta para 
alinear investigaciones y configurar un campo paradigmático alternativo a una, también, actual mirada global de la sociedad y sus procesos, la tecnocráticaeconomicista, pero cuyo basamento son los supuestos de la escasez y el equilibrio que responden a un tipo reduccionista de ciencia.

Si bien esta presentación no es la ocasión para detallar la composición y los alcances de una perspectiva sistémica y compleja, dicho en forma sucinta, puede indicarse que desde sus formas de observación se despliega, sin sorprendernos, el acelerado incremento de las actuales y potenciales conexiones de los componentes de la sociedad y los procesos que posibilitan estados emergentes, imprevistos e inestables cuyo funcionamiento no está determinado por centros o jerarquías. Justamente, estas manifestaciones, que son típicas en la sociedad contemporánea y recurrentes en nuestra región, son las que han dificultado la comprensión y anticipación de sus tendencias por parte de teorías más convencionales.

Las ventajas de la perspectiva son evidentes. Desde la mirada tradicional, la sobreproducción de incertidumbres se interpreta como expresión de desviaciones y anomalías que deben corregirse controlando sus causas. Es decir, desde prácticas políticas conservadoras y orientadas al control. Desde la propuesta, por el contrario, las incertidumbres son los efectos de estructuras y procesos dinámicos relacionados entre sí y que, en esa misma relación, generan estos estados y que a propósito de ello, evocan los conceptos sistémicos de sinergia, retroalimentación positiva y de auto-organización (Arnold \& Osorio, 2008). La teoría sistémica y de la complejidad asume que la evolución de la sociedad entrega las mejores chances al conflicto, lo que deja sin sustento definirlo como un problema y a la integración como una meta. Para mayor abundamiento, gran parte de los fenómenos sociales que nos interesan se comportan como oscilando entre el orden y el desorden. Ello abre paso a la necesidad de una comprensión que permita observar fenómenos sociales emergentes (imprevistos y novedosos), la inestable unidad de la sociedad (pérdida de centro) y los permanentes desequilibrios ("crisis") que la colocan, desde el punto de vista de una observación tradicional, al borde del caos. Por eso, el enfoque sistémico y de la complejidad es una convincente oferta para alinear nuestras producciones, especialmente cuando se indican como características centrales de la sociedad, y de nuestra región en particular, la diversidad y la versatilidad.

Esta perspectiva también se abre a las múltiples descripciones con que indica la sociedad. Estas son abordadas y explicadas en función de las operaciones de observadores. Tal apertura se distancia de las concepciones esencia-

\section{8/ REVISTA DE SOCIOLOGÍA 25}


listas o de pensamiento único que impregnan las descripciones ideologizadas y normativas de la sociedad. Con sus distinciones los investigadores pueden indicar las formas con que se van componiendo, extendiendo, renovando o diversificando las "realidades" sociales. Estos registros al reintroducirse como información (sociológica o pública) posibilitan tomar en cuenta comunicaciones que permanecen excluidas de las corrientes centrales de la sociedad. Es decir: hacen que lo que está ausente pueda estar presente (algo así señala De Sousa Santos (2006:26) o las teorías de la "otredad"). Luego se pueden establecer hipótesis con respecto a tendencias o estados probables cuyo conocimiento, en el caso de ser tomado en cuenta, contribuye a aumentar la capacidad reflexiva de la sociedad y, con ello, esclarecer y democratizar las fuentes cognitivas de su toma de decisiones.

Centrar la observación en la complejidad implica asumir los distintos planos que componen la sociedad. Tanto la "realidad" como su observación sociológica se obligan a ser referenciadas, o más bien autorreferenciadas a las operaciones con que se las va definiendo (sea esta una teoría como la propuesta, o intereses, cálculos, contextos, posiciones sociales, etcétera). De este modo, quedan en evidencia operaciones que son admisibles estructuralmente, aunque indeseables desde otros puntos de vista, por ejemplo, las desigualdades programadas a través de mecanismos de inclusión o los daños ambientales provocados por procesos industriales que sostienen nuestros niveles de bienestar. Por eso, como señaló Niklas Luhmann: "si se quiere que se la considere a la sociología como parte de una ciencia de la realidad, esclarecedora del mundo, deberá ubicarse al problema de la complejidad social en el centro de su interés". (1973: 106).

Ciertamente, la producción de un paradigma de sistemas y de la complejidad para las ciencias sociales implica dispositivos de investigación e instrumentos que consideren -o modelen - los distintos contextos, planos y temporalidades de la sociedad, solo así se puede asumir, sin desmoronarse, la constitución paradójica de sus procesos, como por ejemplo, como se dijo, el hecho de que la sociedad sea a la vez la misma y distinta para sus diferentes observadores.

En todos los sentidos antes dichos, el paradigma sistémico y de la complejidad no se desapega de los valores de la ciencia, ni de sus aspiraciones universalistas, pero los asume desde un formato distinto y renovado. Para alcanzar estos propósitos, como se anticipa, esta perspectiva se vincula estrechamente con los denominados "nuevos modos de conocimiento", especialmente con la inter y la transdisciplina. Por otra parte su distancia- 
miento con el normativismo voluntarista no se traduce en indiferencia frente a los problemas sociales, menos en promover el abandono del interés por los cambios o descuidar la valorización del conocimiento aplicado. De hecho, comprender sistémicamente la complejidad implica actuar con más propiedad y efectividad ante las condiciones de la sociedad y así aportar a quienes esperan que nuestras disciplinas les proporcionen no solo apoyo moral sino que tecnologías efectivas para promover la transformación de la sociedad.

El recorrido realizado se sintetiza en un llamado para aprovechar oportunidades que contribuyan a posicionar activamente nuestras producciones a nivel global. Sobre todo, no dar la espalda a la ciencia que caracteriza al siglo veintiuno, ni ignorar las urgencias de información y de transformación que se requieren en la sociedad. Para ello incorporar nuestras producciones a un mundo más global tiene mucho sentido, aporta a la sociedad en todos los sentidos, ya sea para su intervención reparadora o cambio, ya sea por su comprensión sociológica. Sin embargo, antes que nada, para que el fortalecimiento de las ciencias sociales regionales empiece y forme parte de las expectativas, se deben remover los obstáculos internos y externos que impiden aprovechar la globalización de una ciencia que no se diferencia sobre la base de criterios regionales, de posición social o históricos, sino que por sus teorías y temas de investigación.

Finalmente, si se aceptan los argumentos antes expuestos, independientemente que se respalde la opción por las perspectivas sistémicas y de la complejidad, una tarea ineludible de las ciencias sociales regionales es su integración con las nuevas discusiones de las ciencias y promover una apropiación crítica y creativa de sus debates. Para ello hay recursos, están disponibles sus centenarias universidades públicas, los nuevos centros académicos y, especialmente, los eventos que promueven y patrocinan asociaciones como ALAS, cuyas convocatorias y temas son una clara expresión de las complejidades sociales que requieren ser comprendidas, antes de actuar ciegamente sobre ellas - y donde lo simple, lo aislado, es cada vez más escaso-.

En los tiempos actuales, debe subrayarse, se requieren unas ciencias sociales críticas y, a la vez, rigurosas. Ambas condiciones, no son independientes, son los requisitos para la legitimación pública de nuestros conocimientos e indispensables para un "buen hacer". Las posibilidades están abiertas y podemos empezar a sacudirnos.

\section{0/ REVISTA DE SOCOLLoǴA 25}




\section{Referencias bibliográficas}

Ammon, U. (2010). The Hegemony of English, en UNESCO-ISSC 2010. World Social Science Report. Knowledge Divides. United Nations Educational, Scientific and Cultural Organization and International Social Science Council, París, France, pp.154-156.

ARNOLd M. y F. OSORIo (2008). La Teoría General de Sistemas y su aporte conceptual a las Ciencias Sociales. En: La nueva Teoría Social en Hispanoamérica. Introducción a la teoría de sistemas constructivista. Colección Pensamiento Universitario №¹1. Universidad Autónoma del Estado de México, pp. 19-43.

Arnold, M., UrquizA, A. y D. Humala (2011). Recepción del concepto de autopoiesis en las ciencias sociales. Revista Sociológica Año 26, N 73, Universidad Autónoma Metropolitana. (2011) · Revista de la División de Ciencias Sociales y Humanidades publicada por la UAM - Azcapotzalco, pp. 87-108.

Cardoso, F.H. y E. Faletto (1969). Dependencia y desarrollo en América Latina. Siglo XXI, México.

CAStells, M. (1996) La era de la Información. Alianza Editorial. Madrid.

CAStro-Gómez, S. y Grosfoguel, R. (2007). El giro decolonial: reflexiones para una diversidad epistémica más allá del capitalismo global. Bogotá, siglo del hombre editores; Universidad Central, Instituto de Estudios Sociales Contemporáneos y Pontificia Universidad Javeriana, Instituto Pensar.

Chernilo, D. y Mascareño A. (2005). Universalismo, particularismo y sociedad mundial: obstáculos y perspectivas de la sociología en América Latina. Persona y Sociedad, VOL XIX N³3, 2005. Universidad Alberto Hurtado, pp. 15-45.

De Sousa Santos, B. (2006). Renovar la teoría crítica y reinventar la emancipación social (Encuentros en Buenos Aires). CLACSO Libros, Buenos Aires.

Domínguez, J.M. (2012). Global Modernity, Development, and Contemporary Civilization: Towards a Renewal of Critical Theory (Routledge Studies in Emerging Societies)

DusSEL, E. (2000). Europa, modernidad y eurocentrismo. En: Lander, E. La colonialidad del saber: eurocentrismo y ciencias sociales, UNESCO, Venezuela, pp. 59-61.

Escobar, A. (2003). “Mundos y conocimientos de otro modo”. El programa latinoamericano de modernidad/ colonialidad latinoamericano. En Tabula Rasa, Bogotá, Colombia, №1, enero-diciembre de 2003, pp. 56-86.

GERMANÁ, C. (2009). Los desafíos actuales de la teoría social. Algunas consideraciones centrales. En J. Mejía, (ed.) Sociedad, cultura y cambio en América Latina. I Foro Internacional / Encuentro de la Asociación Latinoamericana de Sociología Lima. Universidad Ricardo Palma. pp. 499-512. 
Germani, G. (1962). Política y sociedad en una época de masas: de la sociedad tradicional a la sociedad de masas. Paidós, Buenos Aires.

GINGRAS,Y. \& Mosbah-NATANSON (2010). Where are social sciencies produced?, en UNESCO-ISSC 2010. World Social Science Report. Knowledge Divides. United Nations Educational, Scientific and Cultural Organization and International Social Science Council, París, France, pp.149-153.

GonzÁlez Casanova, P. (2009). Reestructuración de las ciencias sociales: Hacia un nuevo paradigma. En Tavares dos Santos (org.) Mundializacao e sociología crítica da América Latina (pp. 25-49) UFRGS Editora, Brasil.

LUHMANN, N. 1973 [1967]. Ilustración sociológica, en Ilustración sociológica y otros ensayos. Editorial SUR Buenos Aires, pp. 93-138.

Luhmann, N. (1986). The autopoiesis of social system. En F.Geyer \& J. Van der Zouwen (Eds), Sociocybernetic Paradoxes: Observation. Control and Evolution of SelfSteering Systems. London: Sage. pp. 172-192.

MARTINS, P.H. (2011). Interrogando las fronteras del conocimiento sociológico: globalización, descolonización y don (ms).

Maturana H. y F. Varela (1995 [1973]). De máquinas y seres vivos. Autopoiesis: la organización de lo vivo. Editorial Universitaria, Colección El Mundo de las Ciencias, Tercera Edición, Santiago, Chile.

Mejía J. (2009). Producción del conocimiento social y democratización del saber en América Latina. En Sociedad, cultura y cambio en América Latina. I Foro Internacional/ Encuentro de la Asociación Latinoamérica de Sociología. Universidad Ricardo Palma, Lima, Perú.

MejíA, J. (ed.) (2009). Producción del conocimiento social y democratización del saber en América Latina. En J. Mejía (Ed.), Sociedad, cultura y cambio en América Latina. I Foro Internacional / Encuentro de la Asociación Latinoamericana de Sociología Lima. Universidad Ricardo Palma. pp. 493-498.

Mignolo, W. (2010). Desobediencia epistémica, pensamiento independiente y liberación descolonial. En YUYAYKUSUN, Revista del Departamento Académico de Humanidades de la Universidad Ricardo Palma, № 3, noviembre 2010, pp. 17-40. MolinARI, T. (2009). El incierto futuro de las Ciencias Sociales en América Latina. En J. Mejía, (ed.) Sociedad, cultura y cambio en América Latina. I Foro Internacional / Encuentro de la Asociación Latinoamericana de Sociología Lima. Universidad Ricardo Palma. pp. 485-491.

Quijano, A. (2000). Colonialidad del poder, eurocentrismo y América Latina. En E. Lander (Ed.), La colonialidad del saber: Eurocentrismo y ciencias sociales. Perspectivas latinoamericanas. (pp. 193-238). Buenos Aires: CLACSO.

\section{2/ REVISTA DE SOCIOL LGGíA 25}


RIBEIRO, D. (1976). El proceso civilizatorio. De la revolución agrícola a la termonuclear. México: Editorial Extemporáneos S. A.

RoBles, F. (2012). Epistemologías de la modernidad: Entre el etnocentrismo, el racionalismo universalista y las alternativas latinoamericanas. Cinta de Moebio, 45, 169-203.

ScImago. Country Rankings. Subject Area: Social Sciences. [Disponible en http:// www.scimagojr.com]

UNESCO (2005). Informe Mundial de la UNESCO. Hacia las sociedades del conocimiento. Ediciones UNESCO, París.

UNESCO-ISSC (2010). World Social Science Report. Knowledge Divides. United Nations Educational, Scientific and Cultural Organization and International Social Science Council, París, Francia. 